\title{
The importance of particle dispersion in electrical treeing and breakdown in nano-filled epoxy resin
}

\author{
Siyuan Chen ${ }^{a}$, Simon M. Rowland ${ }^{a *}, J_{a m e s}$ Carr $^{b}$, Malte Storm ${ }^{c}$, Kwang-Leong Choy ${ }^{d}$, Adam J. Clancy ${ }^{e}$ \\ *s.rowland@manchester.ac.uk \\ ${ }^{a}$ The University of Manchester, Dept. of Electrical and Electronic Engineering, Manchester, M13 9PL, UK \\ ${ }^{b}$ The University of Manchester, Dept. of Materials, Manchester, M13 9PL, UK \\ ${ }^{c}$ Diamond Light Source Ltd, Harwell Science and Innovation Campus, Didcot, OX12 ODE, UK \\ ${ }^{d}$ Institute for Materials Discovery, University College London, London, WC1E 7JE, UK \\ ${ }^{e}$ Department of Chemistry, University College London, London, WC1E 7JE, UK
}

\begin{abstract}
The addition of nano-fillers has been widely proposed as a method to enhance the dielectric properties of high voltage polymeric insulation, though there are mixed reports in the literature. Here the potential of silica nano-particles to extend the time to failure specifically through resistance to electrical tree growth in epoxy resin is determined. The benefit of silane treating the nano-particles before compounding is clearly established with regard to slowing tree growth and subsequent time to failure. The growth of trees in needle-plane samples is measured in the laboratory with loadings of 1,3 and $5 \mathrm{wt} \%$ nano-filler. In all cases the average times to failure are extended, but silane treatment of the nano-particles prior to compounding yields much superior results. The emergence of a pronounced inception time before tree growth is also noted for the higher-filled, silane-treated cases. The average time to failure of silane-treated $5 \mathrm{wt} \%$ filled material was 28 times that of the unfilled resin. The improvement in performance between the nanocomposites with untreated and treated fillers is attributed to fewer agglomerations and improved dispersion of the filler in the treated cases. Measurements of Partial Discharge (PD) indicated significant differences in PD patterns during the growth of trees in the treated and untreated cases. This distinction may provide a quality control method for monitoring materials. In particular, long periods in which PDs were not measured were observed in the silane-treated cases. Visual imaging of the tree growth in the unfilled material allowed the changing nature of the tree from fine to tree to dark tree to be observed as it grew. Corresponding PD measurements suggest the dark tree is gradually becoming conductive, and that growth of maximum PD measured is dependent on the relative rates of the growth of the tree and its carbonization.
\end{abstract}

Key words - Electrical tree; partial discharge; breakdown; nanocomposite; silane

\section{Introduction}

Polymeric materials have been widely used in high voltage applications for decades. Equally, the use of filler materials to improve aspects of performance or reduce cost has a long trackrecord. For example, silica has been used as a filler in epoxy resin to improve dielectric breakdown strength and thermal properties whilst reducing net cost of cable joints; and aluminum trihydrate has been used as a flame retardant and track retardant in polyolefin cable sheaths. These fillers comprise micrometer-scale particles and are used in tens of weight percent (wt\%). The modified properties of the filled polymer generally exploit some desirable property of the filler which is superior to that of the polymer. Examples of such properties are high thermal conductivity, mechanical stability and flame retardance [1]. The addition of nano-fillers to polymers works differently, modifying the polymer matrix.
Low weight percentages are typically used $(<5 \mathrm{wt} \%)$, and excellent dispersion can create a homogeneous modified polymer [2].

Electrical tree growth is a precursor to failure of high voltage polymeric insulation. Under high divergent electrical fields, long narrow voids are formed associated with partial discharges. These tubes bifurcate leading to characteristic structures resembling botanical trees [3]. The shape and surface chemistry of these trees control the speed of their growth and the time to system failure, which general occurs shortly after the tree accelerates in growth as it extends across the insulation. Whilst using micro-fillers to produce more robust electrical insulation is well established, the study of tree growth in micro-particle filled polymers has been limited because of the difficulty of optically observing growth in opaque materials [4]. Recent developments in X-ray computed tomography (XCT) have enabled three-dimensional (3D) imaging of trees and their 
interactions with micro-fillers to be established [5]. Further, models of the energy of partial discharges and that required to oblate polymer materials have been built, supporting the link between PD and the process of tree growth in time [6].

The nature of nano-filled polymers depends on the host material, the nature of the nano-filler (e.g. chemistry, shape and size), the concentration of the filler, and the processing of the material. Nano-particles have been shown to produce improved mechanical performance at low filler loadings. For example, improvements can be found in tensile modulus, tensile strength and fracture toughness, potentially reducing the cost of highperformance materials [7]. This has made for rapid commercial adoption, particularly because the low loadings of a few percent required to improve performance enables compounding into many commercial polymers [8].

Contradictory reports have been published concerning improvements to dielectric properties through addition of nanofillers. The variability in reported results is generally ascribed to differences in material preparation, and in particular, interfacial chemistry and filler dispersion [9, 10]. However, with breakdown measurements, the nature of the tests may also be critical. Imai et al., for example, showed that nano-filler improves breakdown performance of epoxy under divergent fields, but not under homogeneous fields [11, 12]. Results suggest that nano-fillers may have a pronounced effect on failure through short term electrical tree growth in divergent fields, but a lesser impact on short-term uniform breakdown fields. Tian et al. also saw a reduction in breakdown test strengths if $\mathrm{ZnO}$ nano-filler was added to low density polyethylene, but a marked improvement in divergent field treeing breakdown times (up to a factor of 50 at $10 \%$ loading) [13]. Iizuka et al. also showed that longer-term treeing tests were more sensitive to nano-fillers than short-term tests, and that the type of filler appeared more important than surface treatment of the fillers with a silane coupling agent [14]. Other work on short-term breakdown testing highlights that interpretation of the statistics of breakdown is important. Testing on too few samples cannot give reliable data and the nature of the breakdown distribution shape is as important as its mean $[15,16,17]$.

The treeing phenomenon in nanocomposites has been investigated mainly in epoxy with needle-plane geometries. Several researchers found significantly improved treeing resistance in nanocomposites. Imai et al. [18] found the addition of nano-filler to micro-filled epoxy increased life at constant fields by a factor of 24 . However, $\mathrm{Li}$ et al. report that nanoparticles improve unfilled and micro-filled epoxy average breakdown voltages by less than 10\% [19]. Tanaka found a more complex behavior, with a deterioration in performance at higher fields [20]. Niedernhuber reported that $1 \mathrm{wt} \%$ nano-filler leads to improved resistance to electrical treeing in epoxy, but $5 \mathrm{wt} \%$ worsened performance [21]. Tsekmes et al. had similar results; poor performance at higher loading was attributed to structural defects and perhaps enhanced water uptake [22].

A feature of electrical treeing is that there is often an inception period after the application of the electric field during which no treeing is evident. In one of the few reports on this, Chen et al. suggest that initiation times in both pure and microfilled epoxy are improved by inclusion of nano-filler [23].

In summary, the literature shows that nano-fillers offer large potential improvements in extending time-to-failure through tree growth, but have a smaller impact on short-term breakdown strength. But any gains depend on material preparation. This paper confirms the impact of dispersion and surface modification of silica nano-particles, specifically on life expectancy in the presence of electrical treeing in epoxy resin. The paper includes PD measurements which identify a significant difference in the mechanisms of tree growth as a result of the presence of nano-filler and the quality of its dispersion.

\section{Experimental}

\subsection{Electrical treeing test}

Materials were tested in the well-established needle-plane geometry. Steel needles, by Ogura ${ }^{\circledR}$, had a tip radius of $3 \mu \mathrm{m}$ and $30^{\circ}$ angle, and the distance between the needle tip and the earth plane was $2 \mathrm{~mm}$. An $\mathrm{HV}$ amplifier delivered $50 \mathrm{~Hz}$ voltage at $13 \mathrm{kV}$ rms as shown in Fig. 1.

Partial discharge (PD) signals were collected by an Omicron MPD 600 system. A balanced circuit including the test sample was used according to IEC 60270. The threshold for PD signal measurement was set at $2 \mathrm{pC}$. The needle tip and associated trees were imaged using a conventional camera and lens. More detail of the experimental arrangement is given in [5].

\subsection{Material preparation}

The hot curing epoxy resin system was Araldite ${ }^{\circledR}$ CY225/Aradur® HY925, from Huntsman Advanced Materials, which has a relatively low viscosity and long gel time, facilitating the compounding process. The epoxy resin is a colorless bisphenol-A epoxy resin while the hardener is an anhydride curing agent with an amber color. The nano-filler is a fumed silica powder from Sigma-Aldrich with a mean particle size of $\sim 7 \mathrm{~nm}$.

The epoxy resin was mixed with the hardener in the ratio of 100:80 by weight, and then stirred for 5 minutes using magnetic

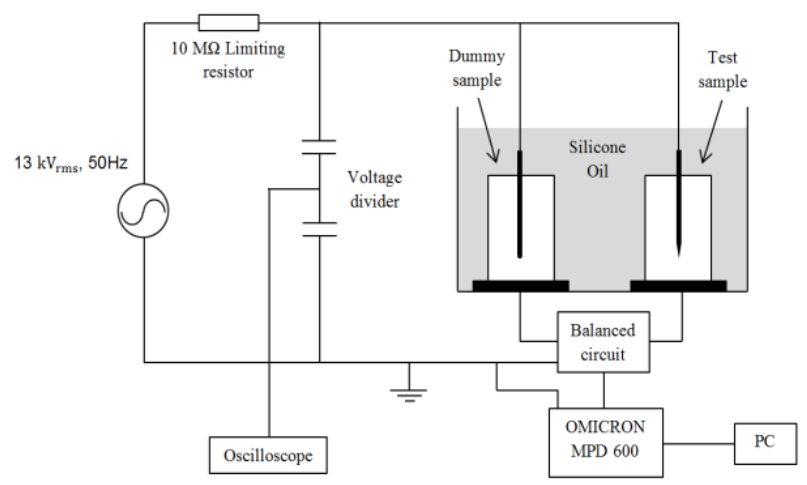

Fig. 1. Experimental circuit for electrical treeing tests. 


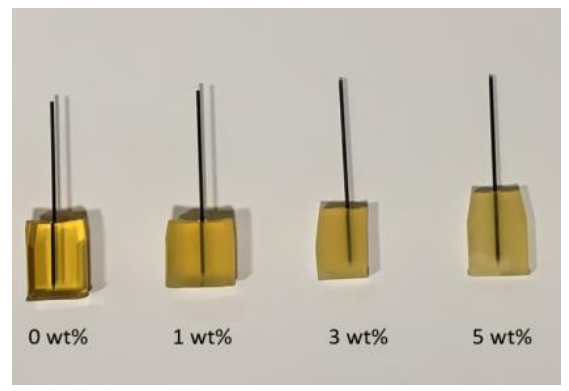

Fig. 2. Epoxy resin sample filled with various levels of nano-filler. Samples have been ground and polished for imaging, and are $\sim 20 \mathrm{~mm}$ wide.

bars. For unfilled samples, the mixture was then degassed in a vacuum oven for 30 minutes to remove air bubbles, and then decanted into PTFE molds. The steel needle was held by a metal cap to provide a $2 \mathrm{~mm}$ gap between the needle tip and the bottom surface. In the case of a filled system, the filler was added manually into the epoxy according to required loading levels and then the mixture was sonicated to minimize aggregate formation. The sonication used a Qsonica ${ }^{\circledR}$ Q700 at $700 \mathrm{~W} / 20 \mathrm{kHz}$. Samples were cured for $6 \mathrm{~h}$ at $80^{\circ} \mathrm{C}$ and then post-cured at $130{ }^{\circ} \mathrm{C}$ for $10 \mathrm{~h}$. Samples were kept dry in a desiccator after preparation.

With the intention of improving the processibility of the nano-composite, some batches of nano-particles were surface treated before compounding, to generate primary amine groups at the interface between the epoxy matrix and the nanoparticles. The silica $(2 \mathrm{~g})$ was bath sonicated in dimethylformamide $(50 \mathrm{~mL})$ for 15 minutes. Separately, 3aminopropyltriethoxy silane $(0.8 \mathrm{mg})$ was dissolved in methanol $(5 \mathrm{~mL})$ before adding dropwise to the silica dispersion and stirring at room temperature for 16 hours. The mixture was filtered and washed with tetrahydrofuran $(50 \mathrm{~mL})$ and dried at $100^{\circ} \mathrm{C}$. A proofing Ninhydrin test was carried out to check satisfactory silanization.

After fully curing and post-curing, all unfilled samples were machined and polished to $\sim 5 \mathrm{~mm}$ thickness. Fig. 2 shows samples with and without nano-filler. With the addition of fillers at only $1 \mathrm{wt} \%$, accurate imaging of trees optically became challenging so XCT was also used [24].

Table 1 summarizes the samples fabricated and the nomenclature used throughout this paper. Fig. 3 shows typical examples of SEM images used to verify nano-particle distribution. These show the existence of agglomerations, especially in the epoxy filled with untreated nano-filler particles; with silane treatment there are few agglomerations and so dispersion is much improved. For the silanized TNF

Table 1. A list of samples tested.

\begin{tabular}{|l|l|c|}
\hline $\begin{array}{c}\text { Sample } \\
\text { name }\end{array}$ & \multicolumn{1}{|c|}{ Description } & $\begin{array}{c}\text { Number } \\
\text { made }\end{array}$ \\
\hline UF & Unfilled & 6 \\
\hline NF1 & $1 \mathrm{wt} \%$ untreated nano-silica & 7 \\
\hline NF3 & $3 \mathrm{wt} \%$ untreated nano-silica & 7 \\
\hline NT5 & $5 \mathrm{wt} \%$ untreated nano-silica & 6 \\
\hline TNF1 & $1 \mathrm{wt} \%$ silane-treated nano-silica & 6 \\
\hline TNF3 & $3 \mathrm{wt} \%$ silane-treated nano-silica & 6 \\
\hline TNF5 & $5 \mathrm{wt} \%$ silane-treated nano-silica & 6 \\
\hline
\end{tabular}
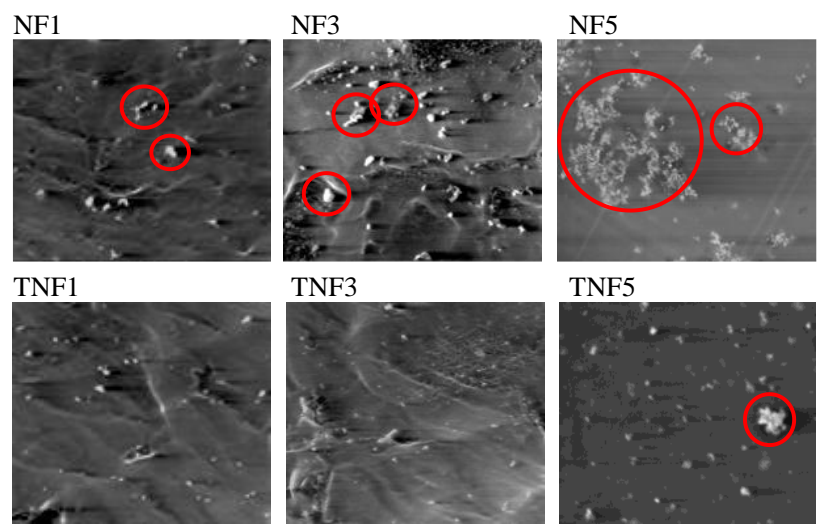

TNF3

TNF5
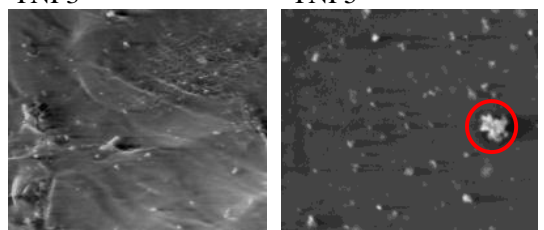

$2 \mu \mathrm{m}$

Fig. 3. SEM images of $1 \mathrm{wt} \%, 3 \mathrm{wt} \%$ and $5 \mathrm{wt} \%$ nano-silica filled epoxy without surface treatment (above) and with surface treatment (below). Examples of filler agglomerations are highlighted by red circles.

samples, the reduction in perceived particulate content is due to the better dispersion of the lipophilic-treated samples in the epoxy precursors, with the resultant individual particles being at the limit of the SEM resolution. Conversely, the as-received $\mathrm{SiOx}$ nanoparticles form larger agglomerates readily seen by SEM.

\section{Results}

To describe the influence of adding nano-particles into epoxy resin, treeing features in unfilled and nano-filled systems are compared. The inception time, $\mathrm{T}_{\mathrm{IN}}$ (the time from voltage application to the appearance of observable partial discharges), the time to breakdown, $\mathrm{T}_{\mathrm{BD}}$ (the time from inception to irreversible dielectric failure), partial discharge evolution and the tree structure are used to describe the electrical trees in different compounds. Some tests were halted before failure to enable imaging of the trees by XCT. In these cases times to breakdown are not recorded.

\subsection{Unfilled epoxy resin}

Two distinguishable types of tree branch were observed using optical imaging: The first looks dark under the backlight and usually has channel diameters of $>2 \mu \mathrm{m}$; the second branch-type appears much lighter and has narrower tubes of diameter $<1 \mu \mathrm{m}$, shown in Fig. 4. Following the description by Zheng et al. [25] and Iddrissu et al. [26], the darker channel is called a 'dark tree' and the other a 'fine tree'. The growth of the dark tree is consistent with typical branch-tree growth described in the literature [24]. Comparisons for the fine tree are harder to find, probably due to imaging challenges [25]. All samples contained these two tree types, and they usually occurred at the same time, with fine trees growing in advance of dark trees. Fig. 5 shows the development in length of the two tree types with time. As reported previously, breakdown follows after dark trees have developed through the fine tree network [25]. It is important to note that the distinction between what is a fine tree and a dark tree in images is presently subjective. It is likely 

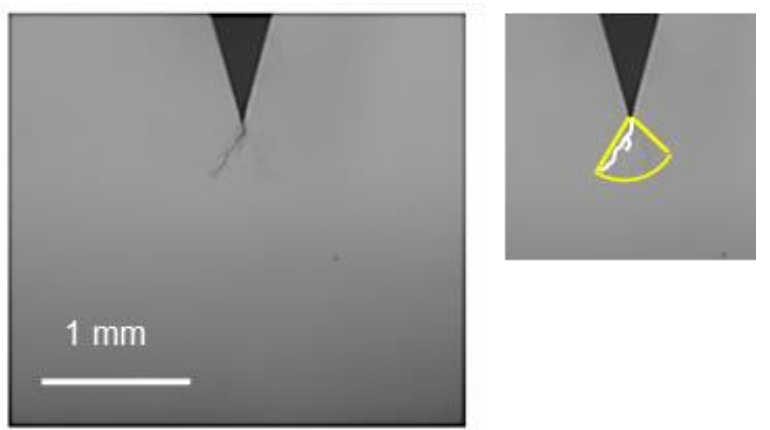

Fig. 4. Image of an electrical tree in unfilled epoxy sample UF2 after $435 \mathrm{~s}$. The dark tree is readily seen and has a length of $390 \mu \mathrm{m}$ and is dominated by one branch. The fine tree is harder to discern, of similar length and has a more symmetric complete bush structure encompassing the dark tree. The image on the right shows the dark tree emphasized by a superimposed white line, and the outline of the fine tree is given in yellow.

that these are not binary states and there is a continuum of tree development.

The times for tree initiation, $\mathrm{T}_{\mathrm{IN}}$, and the time between initiation and breakdown, $\mathrm{T}_{\mathrm{BD}}$, for each of the unfilled samples tested are given in Table 2. There is considerable consistency in $T_{B D}$ values at $\sim 40$ minutes for samples UF2 (featured in Figs. 5 and 6), UF3, UF4 (but with a longer initiation time), and UF6. Only UF1 and UF5 yielded substantially longer and shorter lifetimes respectively.

Fig. 6 shows the partial discharge characteristics of UF2 during tree growth. This sample is chosen to illustrate the differences in PD activity as light and dark trees develop. In the first 420 seconds, during early tree-growth (Stage 1), the PD magnitude gradually increased to $\sim 40 \mathrm{pC}$. The PD rate in this period quickly increased to about 80 per cycle at 240 seconds and thereafter varied between 50 and 80 per cycle. After the early tree-growth stage, when the fine tree extended further but the dark tree did not, no PD was detected. Around 700 seconds after initiation, some sporadic PDs re-ignited with a magnitude of $20 \mathrm{pC}$ but the PD number still remained low. Even in the later

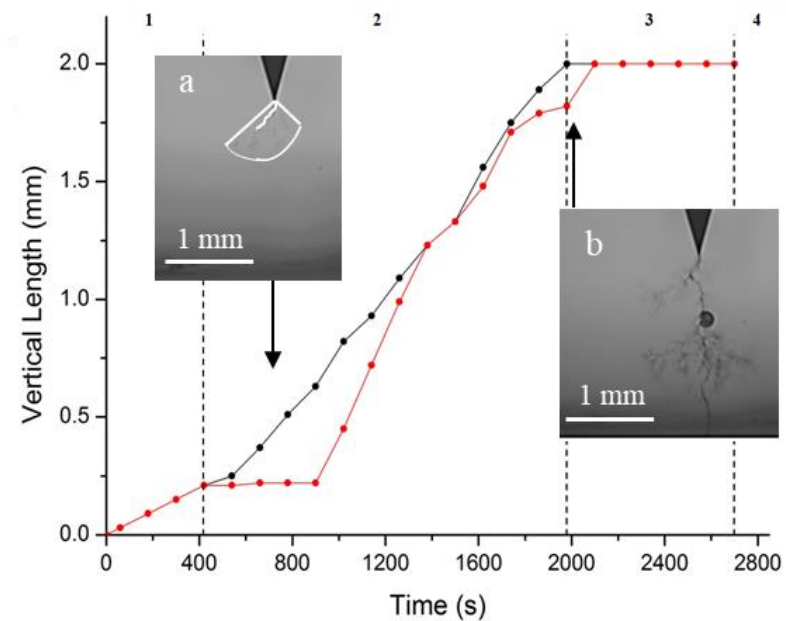

Fig. 5. The growth of the tree in UF2, also shown in Fig. 4. The black line shows the growth of the fine tree and the red line the growth of the dark tree. Treeing stages: (1) the fine and dark tree grow at the same rate, (2) the fine tree leads the dark tree, (3) the fine tree has crossed the insulation, (4) breakdown. Images of the tree are shown at: (a) $745 \mathrm{~s}$ and (b) $2015 \mathrm{~s}$.
Table 2. Characteristic timings for each sample tested.

\begin{tabular}{|c|c|c|c|}
\hline & Sample ID & $\begin{array}{c}\mathbf{T}_{\mathrm{IN}}, \\
\text { initiation } \\
\text { time (mins) }\end{array}$ & $\begin{array}{c}\mathrm{T}_{\mathrm{BD}}, \text { time from } \\
\text { initiation to } \\
\text { breakdown (mins) }\end{array}$ \\
\hline \multirow{7}{*}{ 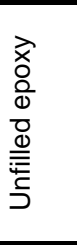 } & UF1 & 2 & 71 \\
\hline & UF2 & 0 & 44 \\
\hline & UF3 & 0 & 41 \\
\hline & UF4 & 20 & 46 \\
\hline & UF5 & 0 & 23 \\
\hline & UF6 & 0 & 46 \\
\hline & Mean & 3.7 & 45.2 \\
\hline \multirow{8}{*}{ 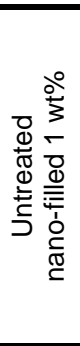 } & NF1-1 & 0 & 121 \\
\hline & NF1-2 & 0 & 102 \\
\hline & NF1-3 & 0 & 73 \\
\hline & NF1-4 & 0 & 99 \\
\hline & NF1-5 & 0 & 113 \\
\hline & NF1-6 & 3 & 83 \\
\hline & NF1-7 & $<1$ & $\begin{array}{c}\text { Used for XCT after } \\
1.8 \mathrm{~h} \\
\end{array}$ \\
\hline & $\begin{array}{c}\text { Mean } \\
\text { (excludes NF1-7) } \\
\end{array}$ & 0.5 & 98.5 \\
\hline \multirow{8}{*}{ 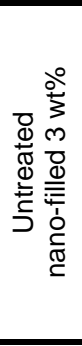 } & NF3-1 & 12 & 236 \\
\hline & NF3-2 & 2 & 195 \\
\hline & NF3-3 & 0 & 154 \\
\hline & NF3-4 & 0 & 167 \\
\hline & NF3-5 & 5 & 137 \\
\hline & NF3-6 & 0 & 112 \\
\hline & NF3-7 & 0 & $\begin{array}{c}\text { Used for XCT after } \\
2.2 \mathrm{~h}\end{array}$ \\
\hline & $\begin{array}{c}\text { Mean } \\
\text { (excludes NF3-7) } \\
\end{array}$ & 3.17 & 166.8 \\
\hline \multirow{7}{*}{ 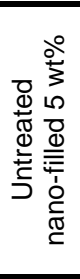 } & NF5-1 & 0 & 98 \\
\hline & NF5-2 & 3 & 212 \\
\hline & NF5-3 & 0 & 158 \\
\hline & NF5-4 & 0 & 121 \\
\hline & NF5-5 & 0 & 115 \\
\hline & NF5-6 & 78 & Did not break down \\
\hline & $\begin{array}{c}\text { Mean } \\
\text { (excludes NF5-6) } \\
\end{array}$ & 0.6 & 140.8 \\
\hline \multirow{7}{*}{ 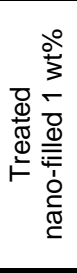 } & TNF1-1 & 0 & Did not break down \\
\hline & TNF1-2 & 3 & 62 \\
\hline & TNF1-3 & 0 & 49 \\
\hline & TNF1-4 & 7 & 86 \\
\hline & TNF1-5 & 0 & 123 \\
\hline & TNF1-6 & 5 & 173 \\
\hline & $\begin{array}{c}\text { Mean } \\
\text { (excludes TNF1-1) }\end{array}$ & 2.5 & 98.6 \\
\hline \multirow{7}{*}{ 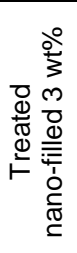 } & TNF3-1 & 2 & 243 \\
\hline & TNF3-2 & 4 & 931 \\
\hline & TNF3-3 & 29 & 1080 \\
\hline & TNF3-4 & 0 & 794 \\
\hline & TNF3-5 & 15 & 991 \\
\hline & TNF3-6 & 0 & 554 \\
\hline & Mean & 8.33 & 765.6 \\
\hline \multirow{7}{*}{ 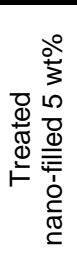 } & TNF5-1 & 8 & 1334 \\
\hline & TNF5-2 & 204 & 1480 \\
\hline & TNF5-3 & 30 & 1057 \\
\hline & TNF5-4 & 52 & 1389 \\
\hline & TNF5-5 & 0 & 962 \\
\hline & TNF5-6 & 97 & Did not break down \\
\hline & $\begin{array}{c}\text { Mean } \\
\text { (excludes TNF5-6) }\end{array}$ & 58.8 & 1244.4 \\
\hline
\end{tabular}




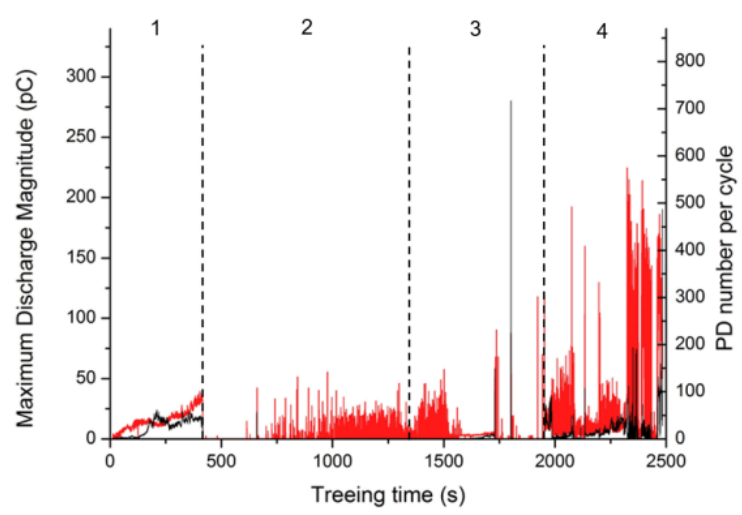

Fig. 6. The maximum discharge magnitude (red) and number of discharges per cycle (black) during the tree growth in the unfilled sample UF2 shown in Figs. 4 and 5. Periods 1-4 are marked for comparison with Fig. 7.

extension stage at $\sim 1500$ seconds, when sporadic PDs appeared with a higher magnitude up to $52 \mathrm{pC}$, the $\mathrm{PD}$ rate remained low (1 or 2 per cycle). During the pre-breakdown stage from $\sim 2000 \mathrm{~s}$, the trend in PD rate started to increase again and increased in magnitude with time. Some significant bursts in magnitude occurred in this stage, and when the tree was approaching breakdown the magnitude became the highest value recorded at $210 \mathrm{pC}$ and the rate reached 480 per cycle. These observations suggest, as identified previously [25], that only growth of the dark trees sustains measurable PD activity and that the interpretation of what is a dark tree in Figs. 4, 5 and 6 may be ambiguous. Certainly the growth of the magnitude of PD appears to be associated with the growth in length of the dark tree, rather than the size of the fine tree structure, as shown in Fig. 7. This shows the maximum value of PD recorded up to a given time as a function of tree length. Each point plotted identifies that the maximum PD value recorded increased when the tree got to that specific length. This illustrates that the maximum PD magnitude is proportional to the dark tree length in Stages 1 and 3, but not in Stage 2, during which the dark tree

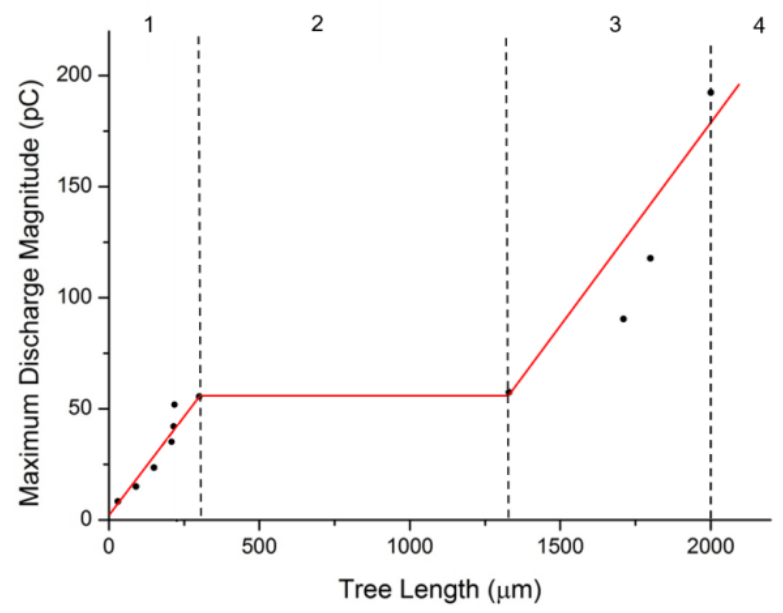

Fig. 7. Maximum PD magnitude up to a given time against the dark tree length in the unfilled epoxy UF2 sample shown in Figs. 4, 5 and 6. There are two periods, labeled ' 1 ' and ' 3 ', in which the PD magnitude is proportional to tree length. The maximum PD did not increase during the second period. In period 4 the tree has crossed the insulation.

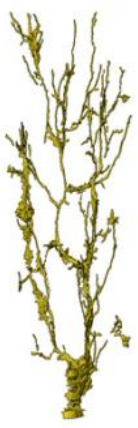

(a)

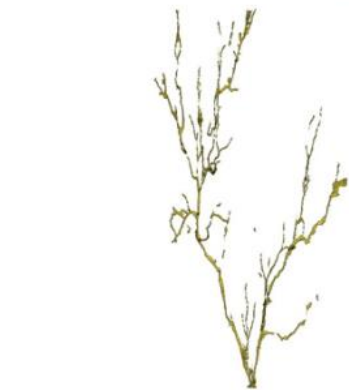

(b)
Fig. 8. $3 \mathrm{D}$ rendering of electrical trees imaged using XCT grown at $13 \mathrm{kV}$ in: (a) $1 \mathrm{wt} \%$ nano-filled sample after 1.8 hours and (b) a $3 \mathrm{wt} \%$ nanofilled sample after 2.2 hours.

is seen to grow without increase in maximum discharge magnitude. This is discussed later in the paper.

\subsection{Untreated nano-filled epoxy resin}

Table 2 gives the treeing data for the samples in which the nano-filler was not silane treated. Although the samples had reasonable transparency (as shown in Fig. 2), it was still found to be a challenge to directly observe the tree structure or length optically with any certainty, so a graph of growth equivalent to Fig. 5 is not possible in these cases.

Whilst there was no discernable improvement in tree initiation times for these materials, there was a marked increase in the breakdown times; in particular the $3 \mathrm{wt} \%$ and $5 \mathrm{wt} \%$ cases performed better than the $1 \mathrm{wt} \%$ material. On average the $3 \mathrm{wt} \%$ material survived longer than the $5 \mathrm{wt} \%$ material.

Fig. 8 shows reconstructions of the trees imaged by XCT from a $1 \mathrm{wt} \%$ nano-filled sample (NF1-7) after 108 minutes and a $3 \mathrm{wt} \%$ nano-filled sample NF3-7 energized for 132 minutes. These respectively have 3D fractal dimensions of 1.7 and 1.6. The mean channel diameter is larger in the $1 \mathrm{wt} \%$ case at $2.8 \mu \mathrm{m}$ compared with $2.0 \mu \mathrm{m}$ in the $3 \mathrm{wt} \%$ case. These figures are indicative of typical branch trees in unfilled epoxy resin [3].

Fig. 9 shows the evolution of partial discharges in sample NF1-5 over its lifetime of nearly 2 hours. Larger and more

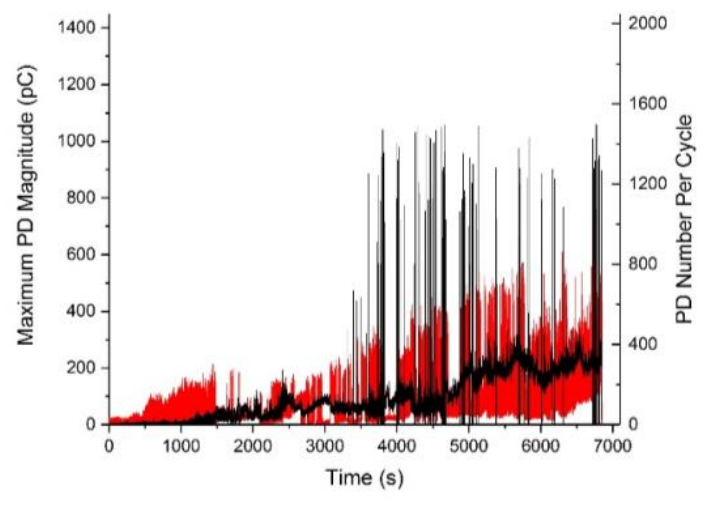

Fig. 9. Maximum partial discharge magnitude (red) and the number of discharges per cycle (black) in sample NF1-5. 
frequent discharges are seen than in the unfilled sample shown in Fig. 6. Also the growth of the PD activity is continuous in time and does not exhibit the interruptions experienced in the unfilled material. This is typical of the nano-filled materials, and is a marked difference from the unfilled epoxy. Table 3 gives averaged values over all failed samples in each category. This shows that the materials with filler consistently gave higher rates and magnitudes of PD compared to the unfilled samples, even though the former lasted longer in testing.

Table 3. PD activity after tree initiation over the period from tree inception to failure, and averaged over all failed samples of each type.

\begin{tabular}{|l|l|l|l|l|}
\hline Sample & $\begin{array}{l}\text { Total } \\
\text { number } \\
\text { of PDs }\end{array}$ & $\begin{array}{l}\text { Average } \\
\text { rate }\left(\mathbf{s}^{-1}\right)\end{array}$ & $\begin{array}{l}\text { Total } \\
\text { energy } \\
(\mathbf{J})\end{array}$ & $\begin{array}{l}\text { Maximum } \\
\text { magnitude } \\
(\mathbf{p C})\end{array}$ \\
\hline \hline UF & $1.21 \times 10^{5}$ & 54 & 0.02 & 303.2 \\
\hline NF1 & $4.66 \times 10^{7}$ & 6561 & 4.21 & 594.4 \\
\hline NF3 & $5.11 \times 10^{7}$ & 6132 & 5.13 & 604.0 \\
\hline NT5 & $4.79 \times 10^{7}$ & 7400 & 7.80 & 487.5 \\
\hline TNF1 & $2.21 \times 10^{7}$ & 347 & 0.31 & 211.8 \\
\hline TNF3 & $1.97 \times 10^{7}$ & 297 & 0.29 & 456.2 \\
\hline TNF5 & $2.80 \times 10^{7}$ & 27 & 0.39 & 388.1 \\
\hline
\end{tabular}

\subsection{Treated nano-filled epoxy resin}

The time for tree initiation, $\mathrm{T}_{\mathrm{IN}}$, and subsequent time-tofailure, $\mathrm{T}_{\mathrm{BD}}$, are given for surface-treated nano-particle filled epoxy in Table 2. The performance at 3 and $5 \mathrm{wt} \%$ loading is significantly better than at $1 \mathrm{wt} \%$, and the 3 and $5 \mathrm{wt} \%$ loading is substantially better than for the equivalent untreated materials. In particular, the growth times in the $5 \mathrm{wt} \%$ treated materials are 27.5 times longer than for the unfilled material. This is discussed in more detail later.

The PD characteristics of the surface-treated nano-filled materials were very different from the untreated filled epoxy. The typical example in Fig. 10 shows that the PDs were not continuous. This was also the case for the unfilled material. Most extinction periods in the treated filled materials were found to be at least 10 times longer than seen in unfilled samples and the longest extinction period was almost 2 hours. The overall maximum magnitude still showed an increasing trend to

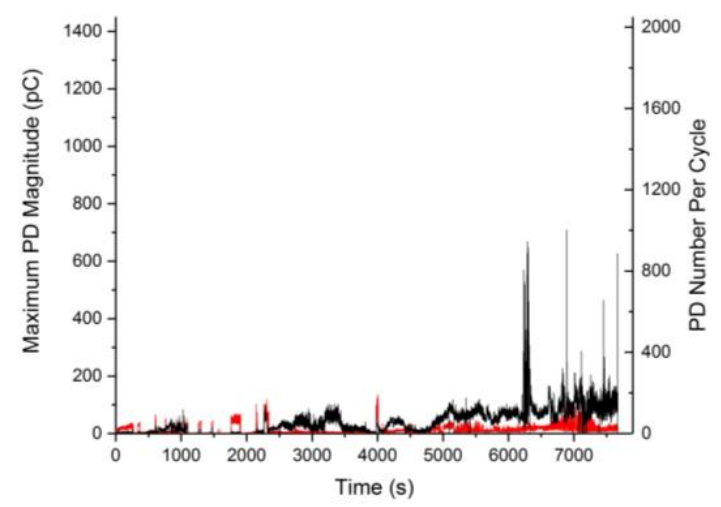

Fig. 10. Maximum partial discharge magnitude (red) and the number of discharges per cycle (black) in sample TNF1-5.
$550 \mathrm{pC}$, while only in the last hour before failure was there an increase in frequency of typical mid-sized discharges (from $80 \mathrm{pC}$ to $110 \mathrm{pC}$ ) between the larger events. Table 3 shows that discharges were smaller in magnitude and frequency than in the untreated cases. Seemingly, much less power was converted by the discharges in the treated material before failure despite the much greater lifetimes observed in the 3 and $5 \mathrm{wt} \%$ cases.

\section{Discussion}

The increase in times to failure associated with filling epoxy resin with micro-sized filler particles has been associated with tree branches having to grow around the particles $[27,5]$. This deviation in direction is associated with slowing the tree growth, and perhaps changing the nature of the macroscopic tree shape [5]. This physical deviation of channel or branch growth is necessary if the filler particle is larger than the tree channel diameter of several microns, because the tree cannot grow through the inorganic filler material, and the channel cannot engulf the particle. The nature of interactions between nano-filler particles and a tree channel must be very different from this model. This is because the scale of a tree channel, typically of width 0.3-5 $\mu \mathrm{m}$, is much greater than the scale of a nano-particle as shown in Fig. 11 and [28]. It is reasoned that, as it grows, a channel interacts directly with a single filler particle larger than itself, however the growth of such a channel is unlikely to be so heavily influenced by individual nanoparticles. Changes to tree growth behavior as a result of nanofillers may be argued to be because of modification of the surrounding polymer through which the tree grows [2]. It follows that if the nano-particles do not change the host polymer, they will have minimal effect on tree growth. Excellent dispersion and surface modification implies a more consistent and fundamental change to the host polymer, optimizing the impact of the nano-filler. In contrast, if nanoparticles agglomerate into micron-sized features they may interact directly with the tree channels.

It seems therefore that discussion of the impact of nano-filler on tree growth might be interpreted as either impact of the nanoparticles on the properties of the polymer matrix, or through impact as micro-scale agglomerates. This might be expressed

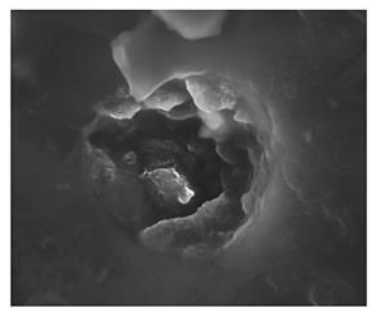

(a)

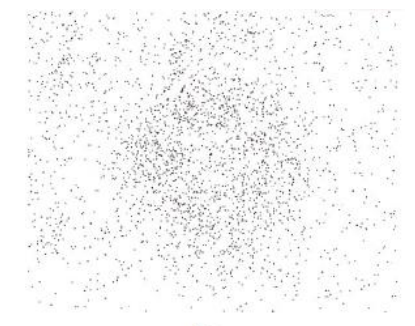

(b)
Fig. 11. (a) SEM image showing the cross-section of a tree channel in 5 wt\% nano-silica filled epoxy sample NT5-1. (b) Si element map of the same image collected from EDX showing the distribution of nanoparticles. There is an apparent increase of nano-particles in the center of the channel because of the inclined surface giving a greater surface area. 
respectively as changing the continuum in which the channels grow, and adding discrete features. These two expressions may be in direct competition as we note that the presence of agglomerates reduces the effective number density of nanoparticles available to modify the polymer.

Fig. 3 illustrates that silanation of the nano-filler particles greatly reduced the number and size of agglomerates seen in the filled polymer. This is consistently the case for the higher loadings of the surface-treated nano-fillers. Apart from the agglomerations, the distribution of nano-particles is very uniform throughout the polymer in all cases, showing that the dispersion methodology works well. Table 4 is a compilation of SEM measurements of the separation of particles. These are difficult to interpret, with the distances in the untreated cases being similar at all three weight loadings, probably because the increase in agglomerations at higher loadings reduces the effective number of individual nano-particles available for dispersion, and because the filler particles are not readily observed individually by SEM because of their size. In the surface-treated cases however, a greater wt $\%$ leads to reduced particle separation, as expected. At $3 \mathrm{wt} \%$ and $5 \mathrm{wt} \%$ of the treated filler particles, separation reduces to $399 \mathrm{~nm}$ and $198 \mathrm{~nm}$ respectively. It should be noted that these measured particle separations are not 3D nearest neighbor distances but are taken from 2D SEM cross-sections. Actual 3D particle separation will be smaller.

A summary of breakdown times, $\mathrm{T}_{\mathrm{BD}}$, for all samples taken to failure is shown in Fig. 12. It was found that no matter whether the particle surface was treated or not, epoxy filled with nano-silica enhanced the treeing strength in comparison to the unfilled one. Whilst reports in the literature vary considerably,

Table 4. Experimentally determined nearest neighbor distance in nanocomposites.

\begin{tabular}{|c|c|c|}
\hline \multicolumn{2}{|c|}{ Sample description } & $\begin{array}{c}\text { Average nearest neighbor } \\
\text { distance (nm) }\end{array}$ \\
\hline NF1 & $1 \mathrm{wt} \%$ untreated & 568 \\
\hline NF3 & $3 \mathrm{wt} \%$ untreated & 513 \\
\hline NF5 & $5 \mathrm{wt} \%$ untreated & 765 \\
\hline TNF1 & $1 \mathrm{wt} \%$ silane-treated & 432 \\
\hline TNF3 & $3 \mathrm{wt} \%$ silane-treated & 399 \\
\hline TNF5 & $5 \mathrm{wt} \%$ silane-treated & 198 \\
\hline
\end{tabular}

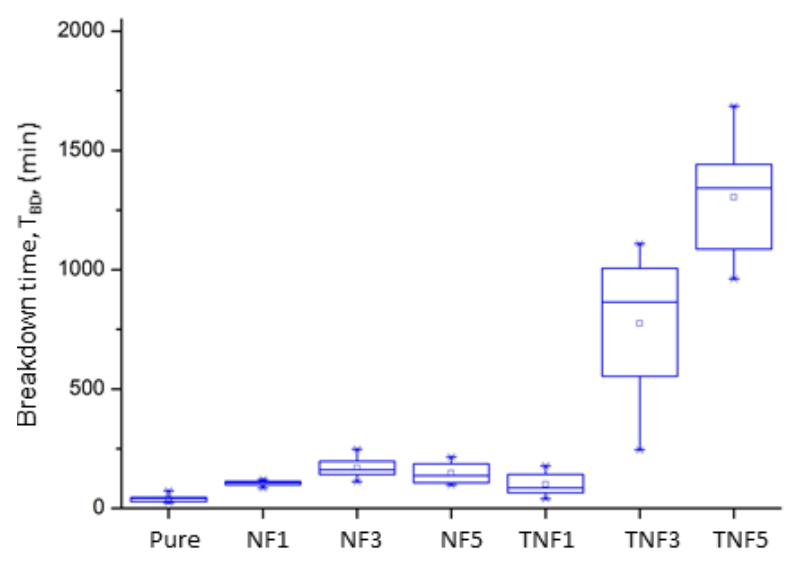

Fig. 12. Time from initiation to breakdown, $T_{B D}$ of nano-silica filled epoxy samples under $13 \mathrm{kVrms}$. Labeled according to Table 2. our results are consistent with observations of [13, 18, 19]. In comparison to the unfilled group, the mean breakdown time was enhanced by factors of 2.2 and 3.7 in the 1 and $3 \mathrm{wt} \%$ untreated samples respectively. At $5 \mathrm{wt} \%$, the breakdown time showed a lower level of improvement than the $3 \mathrm{wt} \%$, being enhanced by a factor of 3.1 only. This reflects results reported by $[12,22]$. The reduction in improvement from the $3 \mathrm{wt} \%$ case may be because a filler value less than $5 \mathrm{wt} \%$ is optimal, but is more likely due to increased levels of agglomeration in the higher filled case. Where agglomeration effectively removes nano-filler number density in the polymer, the improvements in performance are reduced. It can be argued then that, at $5 \mathrm{wt} \%$, agglomeration of untreated particles is offsetting any improvements gained by the additional filler above $3 \mathrm{wt} \%$. This argument is supported by the increase in inter-particle distance at $5 \mathrm{wt} \%$ loading which results from a reduced number of particles due to the agglomeration at higher loadings. It may also be the case that the agglomerates themselves introduce points of weakness in the material.

Samples comprising treated nano-silica showed greater improvements than the untreated cases at 3 and $5 \mathrm{wt} \%$, but there was no significant difference at $1 \mathrm{wt} \%$. Whilst the mean breakdown values of NF1, NF3, NF5 and TNF1 do vary, and are substantially better than the unfilled material, the box and whisker plots show their performance is not radically different: their distributions do overlap. Nonetheless, variation between them may be attributed to combinations of changing density of filler and agglomeration effects. However, at $3 \mathrm{wt} \%$ the average tree growth time increased by a factor of 17 compared to the unfilled material (the equivalent factor was 3.7 in the untreated case). At $5 \mathrm{wt} \%$ a remarkable improvement by a factor of 27.5 was achieved. This is similar to the factor of 24 reported by Imai et al. [18]. This improvement is also associated with reduced particle separation reported above in the treated $5 \mathrm{wt} \%$ case. This enhanced performance can thus be associated with fewer agglomerations, resulting in improved availability of filler, and so optimal impact on the host polymer.

A second marked difference for the treated filled material is the emergence of a significant and consistent tree initiation period at higher filler loadings. These results are consistent with those of Chen et al. [23], who reported the addition of nanoparticles delaying tree inception. Niedernhuber et al. also saw improvements at $1 \mathrm{wt} \%$ loading, but shorter initiation times at $5 \mathrm{wt} \%$ (the latter perhaps because of poor dispersion) [21]. The average initiation period increases with treated filler loading, from 2.4 minutes in $1 \mathrm{wt} \%$ material up to 58.8 minutes at $5 \mathrm{wt} \%$. In the 1,3 and $5 \mathrm{wt} \%$ groups this can be expressed as a proportion of the time from initiation to breakdown $\left(\mathrm{T}_{\mathrm{BD}}\right)$ : The average in each case is $3.2 \%, 0.9 \%$ and $4.2 \%$ respectively. Taking the overall average for all samples with treated filler, the ratio is $2.6 \%$. In each set there is one sample with a particularly long initiation time, so it is unwise to read too much into the comparison between loading levels. However, it is clear that an initiation period is increased with filler loading, and this does not occur if the filler is not surface treated. For all samples the initiation period is short compared to the time to breakdown. 
In all cases, PD magnitude increased as the treeing experiments progressed. Only in the unfilled samples could the visible aspect of tree growth be distinguished and correlated with PD activity directly. The XCT measurement however showed that although the fractal dimension (and so the general shape) of the trees in the $1 \mathrm{wt} \%$ and $3 \mathrm{wt} \%$ cases was similar, the $3 \mathrm{wt} \%$ tree had a diameter of $2.0 \mu \mathrm{m}$ compared with $2.8 \mu \mathrm{m}$ in the $1 \mathrm{wt} \%$ case. This results in a doubling of tree void volume, and so implies a greater energy requirement to grow an equivalent tree length in the $1 \mathrm{wt} \%$ case. This difference is not seen in the total energy associated with PD measured during tree growth (Table 3 ). We conclude therefore that the efficiency of growth is different in each case, and the $3 \mathrm{wt} \%$ material is perhaps more robust against deterioration that then $1 \mathrm{wt} \%$ case. This is consistent with the longer breakdown times witnessed in the $3 \mathrm{wt} \%$ case.

Fig. 7 illustrates that the maximum PD magnitude in the unfilled material is proportional to the dark tree length in Stages 1 and 3, but not in Stage 2 in which the dark tree is seen to grow without increase in discharge magnitude. The two regions of proportional growth (Stages 1 and 3 ) have the same constant of proportionality of $0.18 \mathrm{pC} / \mu \mathrm{m}$, but are offset by $1000 \mu \mathrm{m}$. This is because there is a period (Stage 2) in which the tree grows from $300 \mu \mathrm{m}$ to $1300 \mu \mathrm{m}$ with no increase in the maximum discharge magnitude. It has previously been established that fine trees can grow with no PD being measured [25]. Here we propose that the PD development may be due to the discharge being dependent on the non-conducting length of the dark tree in which discharges can occur. If, during Stage 2, the tree growth is matched by a conversion of a length of the insulating tree to a conducting form adjacent to the needle, the length of the tree which is not conductive remains the same, thus the maximum PD magnitude is unchanged. Therefore, Stage 1 can be described as insulating dark tree growth accompanied by increasing regular PD activity; in Stage 2 the dark tree growth at its tip is insulating but matched by conversion of the base of the tree to a conducting form, and associated with fewer discharges which are fixed in maximum magnitude; in Stage 3 the tree is approaching the planar electrode, and the insulating region of the tree is growing faster than the conducting region of the tree so that PD magnitude increases, again proportionately to the non-conducting length of the tree. Finally in Stage 4 the tree has crossed the insulation and discharges increase in magnitude and frequency as breakdown ensues. This hypothesis matches the results indicating that PD magnitude is dependent on non-conducting tree length [29]. It is also consistent with large-scale interface tracking tests that show that the growth of PD magnitude is limited by track length, and tree growth at a fixed voltage is dependent on carbonization adjacent to the point of field enhancement [30].

The complexity of the description of the stages in tree growth which can be observed in the transparent, unfilled sample demonstrates the challenge of interpretation of the results in the filled opaque samples. The particle separation and agglomeration measurements suggest the silane surface functionalization is effective in reducing the surface energy of the particle and improves the adhesive capability with epoxy resin. The very large improvements in treated nano-filled materials show that the nano-filler is modifying the epoxy to improve its resistance to tree growth. This may be due to a combination of three factors: Firstly, minimizing agglomeration of nano-particles ensures nano-particles are available to be distributed in the polymer and optimize impact on the composite; Secondly, the surface treatment of the fillers may improve the bonding of the fillers with the epoxy, thereby enhancing the composite performance more than the untreated filler; Thirdly, minimizing the presence of agglomerates removes defects in the material which can otherwise offset any benefit the nano-filler might bring.

Partial discharge measurements show a further marked difference between sample types. The rate of PDs is considerably higher and more continuous in the untreated filled materials than in both the unfilled and treated filled materials. This may indicate that the formation of agglomerates and material inhomogeneities actually increases PD activity. This might also explain some findings that higher loadings of nanofiller reduce performance [21]. The XCT information, though scant, illustrates the importance of obtaining microstructure detail of trees in these modified materials. Scans of the $1 \mathrm{wt} \%$ and $3 \mathrm{wt} \%$ unfilled cases shows typical tree shapes as would be observed in unfilled polymers [3], but the diameters of the tree channels are different in each case. This is an important difference, because tree shape and geometry control PD characteristics. This needs further investigation and, in particular, imaging work to interpret the complex PD patterns identified. A key feature of the silane-treated filled cases is the presence of extended periods without PD, which reflect not just a slowing down of tree growth, but probably indicate a different process and morphology. These periods of reduced PD activity are also seen in the unfilled material, and are perhaps representative of more uniform materials. The absence or reduction in PD may be taken as a sign of threat reduction, when in fact it is a sign of a change in the degradation process, and in particular the conversion of part of a dark tree from insulating to conductive. This conversion in conductivity allows further growth of the whole tree structure [31]. Understanding this in more detail is critical for asset managers trying to interpret PD activity in $\mathrm{HV}$ plant.

\section{Conclusions}

Silane treatment of nano-filler was shown to reduce the occurrence of agglomerations in the epoxy resin at all filler loadings. In all cases the addition of nano-particles was seen to improve the treeing-breakdown times of epoxy. Silane treatment of the nano-particle surface radically improved performance, especially at $5 \mathrm{wt} \%$ loading. In addition, silanetreated fillers introduced a small but clear initiation time in all cases.

Detailed review of the conflicting reports in the literature has shown that they are, in fact, consistent with the results and interpretation from the various materials examined here. This resolves ambiguity which is present in the literature, and 
confirms that conflicts in published results are due to differences in material preparation.

Partial discharges show distinct behavior between the silanetreated and untreated cases. The silane-treated material, with much enhanced lifetimes, showed bursty patterns of PD, with extended periods of low discharge activity, whilst the untreated material had continuous and much more predictable behavior. More imaging work is required to confirm this indicates a difference in tree growth behavior, but it is clear that there is a distinct difference in tree channel diameter in the $1 \mathrm{wt} \%$ and $3 \mathrm{wt} \%$ untreated cases.

Visual imaging of the tree growth in the unfilled material allowed the changing nature of the tree from fine to dark to be observed as it grew. Corresponding partial discharge measurements suggest the tree is gradually becoming conductive, and that growth of the largest partial discharges is dependent on the relative rates of the growth of the tree and its carbonization. Interpretation of partial discharge measurements must be treated with caution as periods of sparse activity may represent the tree transitioning into a more threatening state rather than becoming permanently quiescent.

\section{Acknowledgment}

The authors acknowledge EPSRC for support through 'Composite Dielectric Structures with Enhanced Lifetimes' EP/M016234/1, and the Diamond Light Source award MT18215. AJC thanks SCI and the Ramsay Memorial Trust.

\section{References}

[1] I. Plesa, P. V. Notingher, S. Schlogl, C. Sumereder, and M. Muhr, "Properties of Polymer Composites Used in High-Voltage Applications," Polymers, vol. 8, no. 5, 2016.

[2] T. Tanaka, M. Kozako, N. Fuse, and Y. Ohki, "Proposal of a multi-core model for polymer nanocomposite dielectrics," IEEE Trans. Dielectr. Electr. Insul, vol. 12, no. 4, pp. 669-681, 2005.

[3] R. Schurch, J. Ardila-Rey, J. Montana, A. Angulo, S. M. Rowland, I. Iddrissu and R. S. Bradley, "3D Characterization of Electrical Tree Structures," IEEE Trans. Dielectr. Electr. Insul., vol 26, no. 1, 220-228, 2019.

[4] R. Kurnianto, Y. Murakami, N. Hozumi and M. Nagao, "Characterization of Tree Growth in Filled Epoxy Resin: The Effect of Filler and Moisture Contents," IEEE Trans. Dielectr. Electr. Insul., vol. 14, no. 2, 2007.

[5] S. Chen, Z. Lv, J. Carr, M. Storm and S. M. Rowland, "Electrical Tree Growth in Microsilica-Filled Epoxy Resin," Accepted for publication in IEEE Trans. Dielectr. Electr. Insul,.

[6] R. Schurch, S. M. Rowland, and R. S. Bradley, "Partial discharge energy and electrical tree volume degraded in epoxy resin," IEEE Conf. on Electrical Insulation and Dielectric Phen., pp. 820-823, 2015.

[7] S. H. Lim, K. Y. Zeng and C. B. He, "Morphology, tensile and fracture characteristics of epoxy-alumina nanocomposites," Materials Science \& Engineering A, vol. 527. no. 21, pp. 5670-5676, 2010.

[8] Lauterwasser "Small sizes that matter: Opportunities and risks of Nanotechnologies" Allianz report in co-operation with the OECD International Futures Programme, Available:

https://www.oecd.org/science/nanosafety/37770473.pdf

[9] T. Tanaka, "Dielectric nanocomposites with insulating properties," IEEE Trans. Dielectr. Electr. Insul., vol. 12, no. 5, pp. 914-928, 2005.

[10] C. Calebrese, L. Hui, L. S. Schadler, and J. K. Nelson, "A review on the importance of nanocomposite processing to enhance electrical insulation," IEEE Trans. Dielectr. Electr. Insul., vol. 18, no. 4, pp. 938945, 2011.

[11] T. Imai, F. Sawa, T. Ozaki, Y. Inoue, T. Shimizu and T. Tanaka, "Comparison of insulation breakdown properties of epoxy nanocomposites under homogeneous and divergent electric fields," IEEE Conf. on Electrical Insulation and Dielectric Phen., 2006, pp. 306-309.

[12] T. Imai, F. Sawa, T. Yoshimitsu, T. Ozaki and T. Shimizu, "Preparation and insulation properties of epoxy-layered silicate nanocomposite," IEEE Conf. on Electrical Insulation and Dielectric Phen., 2004, pp. 402-405.

[13] F. Tian, Q. Lei, X. Wang, and Y. Wang, "Investigation of electrical properties of LDPE/ZnO nanocomposite dielectrics," IEEE Trans. Dielectrics and Electrical Insulation, vol. 19, no. 3, pp. 763-769, 2012.

[14] T. Iizuka, Y. Ohki and T. Tanaka, "Effects of coupling agent and filler dispersion on V-t characteristics of epoxy/silica nanocomposites," IEEE Int. Symp. on Electrical Insulating Materials, 2008, pp. 60-63.

[15] E. Tuncer, I. Sauers, D. R. James, A. R. Ellis, M. P. Paranthaman, T Aytug, S. Sathyamurthy, K. L. More, J. Li and A. Goyal, "Electrical properties of epoxy resin based nano-composites," Nanotechnology, vol. 18, 025703, 6pp, 2007.

[16] M. Donnay, S. Tzavalas and E. Logakis, "Boron nitride filled epoxy with improved thermal conductivity and dielectric breakdown strength," Composites Sci. and Tech., vol. 110, pp. 152-158, 2015.

[17] S. Virtanen, T. M. Krentz, J. K. Nelson, L. S. Schadler, M. Bell, B. Benicewicz, H. Hillborg and S. Zhao, "Dielectric breakdown strength of epoxy bimodal-polymer-brush-grafted core functionalized silica nanocomposites," IEEE Trans. Dielectr. Electr. Insul., vol. 21, no. 2, pp. 563-570, 2014.

[18] T. Imai, F. Sawa, T. Nakano, T. Ozaki, T. Shimizu, M. Kozako and T. Tanaka, "Influence of temperature on mechanical and insulation properties of epoxy-layered silicate nanocomposite," IEEE Trans. Dielectr. Electr. Insul., vol. 13, no. 2, pp. 445-452, 2006.

[19] Z. Li, K. Okamoto, Y. Ohki and T. Tanaka, "Role of Nano-Filler on Partial Discharge Resistance and Dielectric Breakdown Strength of Micro-A1203 / Epoxy Composites," Int. Conf. on Properties and Applications of Dielectric Materials, 2009, pp.753-756.

[20] T. Tanaka, "Similarity between treeing lifetime and PD resistance in aging mechanisms for epoxy nanocomposites," IEEE Int. Conf. on the Properties and Applications of Dielectric Materials, 2009, pp. 741-744.

[21] J. Niedernhuber and J. Kindersberger, "Electrical treeing in insulating resins with silica nanofillers," IEEE Int. Conf. on Solid Dielectrics, 2013, pp. 828-831.

[22] I. A. Tsekmes, R. Kochetov, P.H.F. Morshuis and J.J. Smit, "AC Breakdown Strength of Epoxy-Boron Nitride Nanocomposites: Trend \& Reproducibility," IEEE Electrical Insulation Conf., 2015, pp. 446449.

[23] Y. Chen, T. Imai, Y. Ohki and T. Tanaka, "Tree initiation phenomena in nanostructured epoxy composites," IEEE Trans. Dielectr. Electr. Insul., vol. 17, no. 5, pp. 1509-1515, 2010.

[24] R. Schurch, S. M. Rowland, R. S. Bradley and P. J. Withers, "Imaging and analysis techniques for electrical trees using X-ray computed tomography," IEEE Trans. Dielectr. Electr. Insul., vol. 21, no. 1, pp. 53-63, 2014.

[25] H. Zheng, S. M. Rowland, I. Iddrissu and Z. Lv, "Electrical treeing and reverse tree growth in an epoxy resin," IEEE Trans. Dielectr. Electr. Insul., vol. 24, no. 6, pp. 3966-3973, 2017.

[26] I. Iddrissu, Z. Lv and S. M. Rowland, "The dynamic character of partial discharge in epoxy resin at different stages of treeing," IEEE Int. Conf. on Dielectrics, vol. 2, pp. 728-731, 2016.

[27] R. Kurnianto, Y. Murakami, N. Hozumi and M. Nagao, "Characterization of tree growth in filled epoxy resin: the effect of filler and moisture contents," IEEE Trans. Dielectr and Electr Insul, vol. 14, no. 2, pp. 427-435, 2007

[28] T. Tanaka, "Similarity between Treeing Lifetime and PD Resistance in Aging Mechanisms for Epoxy Nanocomposites," Int.Conf. on Properties and Appls. of Dielectric Materials, H3, pp. 741-444,, 2009.

[29] Z. Lv, S. M. Rowland, S. Chen and H. Zheng, "Modelling and Simulation of PD Characteristics in Non-Conductive Electrical Trees," IEEE Trans. Dielectr. Electr. Insul., vol. 25, no. 6, pp. 2250-2258, 2018.

[30] S. Morsch, P. D. Bastidas and S. M. Rowland, "AFM-IR Insights into the Chemistry of Interfacial Tracking," Journal of Materials Chemistry A, vol. 5, no. 46, pp. 24508-24517, 2017.

[31] X. Chen, Y. Xu, X. Cao, S. J. Dodd, and L. A. Dissado, "Effect of tree channel conductivity on electrical tree shape and breakdown in XLPE cable insulation samples," IEEE Trans. Dielectr. and Electr. Insul, vol.18 no. 3, pp.847-860, 2011. 